\title{
Retrieval of kinetic temperature and carbon dioxide abundance from non-local thermodynamic equilibrium limb emission measurements made by the SABER experiment on the TIMED satellite
}

\author{
Christopher J. Mertens ${ }^{*} a$, Martin G. Mlynczak ${ }^{a}$, Manuel López-Puertas ${ }^{b}$, \\ Peter P. Wintersteiner ${ }^{c}$, Richard H. Picard ${ }^{d}$, Jeremy R. Winick ${ }^{d}$, Larry L. Gordley ${ }^{e}$, \\ and James M. Russell III $f$ \\ ${ }^{a}$ NASA Langley Research Center, Hampton, Virgina, USA \\ ${ }^{b}$ Instituto de Astrofisica de Andalucia, CSIC, Granada, Spain \\ ${ }^{c} \mathrm{ARCON}$ Corporation, Waltham, Massachusetts, USA \\ ${ }^{d}$ Air Force Research Laboratories, Hanscom AFB, Massachusetts, USA \\ ${ }^{e} \mathrm{G} \&$ A Technical Software, Newport News, Virginia, USA

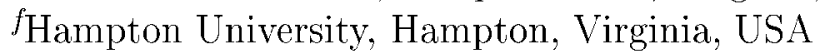

\begin{abstract}
The Sounding of the Atmosphere using Broadband Emission Radiometry (SABER) experiment was launched onboard the TIMED satellite in December, 2001. SABER is designed to provide measurements of the key radiative and chemical sources and sinks of energy in the mesosphere and lower thermosphere (MLT). SABER measures Earth limb emission in 10 broadband radiometer channels ranging from $1.27 \mu \mathrm{m}$ to $17 \mu \mathrm{m}$. Measurements are made both day and night over the latitude range from $54^{\circ} \mathrm{S}$ to $87^{\circ} \mathrm{N}$ with alternating hemisphere coverage every 60 days. In this paper we concentrate on retrieved profiles of kinetic temperature $\left(\mathrm{T}_{\mathrm{k}}\right)$ and $\mathrm{CO}_{2}$ volume mixing ratio (vmr), inferred from SABER-observed $15 \mu \mathrm{m}$ and $4.3 \mu \mathrm{m}$ limb emissions, respectively. SABER-measured limb radiances are in non-local thermodynamic equilibrium (non-LTE) in the MLT region. The complexity of non-LTE radiation transfer combined with the large volume of data measured by SABER requires new retrieval approaches and radiative transfer techniques to accurately and efficiently retrieve the data products. In this paper we present the salient features of the coupled non-LTE $\mathrm{T}_{\mathrm{k}} / \mathrm{CO}_{2}$ retrieval algorithm, along with preliminary results.
\end{abstract}

Keywords: Remote sensing, non-local thermodynamic equilibrium (non-LTE), thermal structure, carbon dioxide, mesosphere, lower thermosphere, middle atmosphere

\section{INTRODUCTION}

On December 7, 2001, NASA launched the Sounding of the Atmosphere using Broadband Emission Radiometry (SABER) experiment onboard the TIMED satellite. The satellite was placed in a 74.1 degree inclined, 625 $\mathrm{km}$ orbit by a Delta II rocket. The SABER instrument is designed to provide measurements of the major radiative and chemical sources and sinks of energy in the MLT region. The primary science goal of SABER is to achieve major advances in our understanding of the structure, energetics, chemistry, and dynamics of the atmospheric region extending from $60 \mathrm{~km}$ to $180 \mathrm{~km}$ altitude. This will be accomplished using the measurement approach of spectral broadband emission radiometry. SABER scans the horizon and observes limb emission in 10 broadband spectral channels ranging from $1.27 \mu \mathrm{m}$ to $17 \mu \mathrm{m}$. The observed limb emission profiles are analyzed to provide vertical profiles, with approximately $2 \mathrm{~km}$ altitude resolution, of the following parameters: $\mathrm{T}_{\mathrm{k}} ; \mathrm{CO}_{2}$, $\mathrm{O}_{3}$ and $\mathrm{H}_{2} \mathrm{O}$ vmr; atomic oxygen and atomic hydrogen; volume emission rates due to $\mathrm{O}_{2}\left({ }^{1} \Delta\right), \mathrm{OH}(\nu=3,4,5)$, $\mathrm{OH}(\nu=7,8,9)$, and $\mathrm{NO}$ at $5.3 \mu \mathrm{m}$; key atmospheric cooling rates, solar heating rates, chemical heating rates,

* Correspondence: E-mail: c.j.mertens@larc.nasa.gov; Telephone: 757-864-2179; Fax: 757-864-6326 
and geotrophic winds. Measurements are made both day and night over the latitude range from $54^{\circ} \mathrm{S}$ to $87^{\circ} \mathrm{N}$ with alternating hemisphere coverage every 60 days.

In the MLT region, SABER measures in each channel - with the exception of the $1.27 \mu \mathrm{m}$ channel, which mainly measures emission from the $\mathrm{O}_{2}\left({ }^{1} \Delta\right)$ electronic transition - infrared radiation emitted by molecules whose vibration-rotation bands are in non-LTE. Non-LTE kinetic processes and non-LTE radiation transfer complicate the analysis and retrieval of the SABER data products, as well as impose a significant computational burden on data processing. New retrieval approaches and radiation transfer techniques are required to accurately and efficiently retrieve the data products from the large volume of SABER non-LTE emission measurements. In particular, the focus of this paper is on the non-LTE $\mathrm{T}_{\mathrm{k}} / \mathrm{CO}_{2}$ retrieval approach.

Kinetic temperature is retrieved from SABER's broadband measurement of $\mathrm{CO}_{2} 15 \mu \mathrm{m} \mathrm{limb}$ emission. This technique was developed more than 30 years ago. ${ }^{1}$ In these early experiments, a basic assumption was that $\mathrm{CO}_{2}$ was well mixed and its volume mixing ratio well known Another key assumption was that the observed $\mathrm{CO}_{2}$ vibration-rotation bands were in LTE. These assumptions were sufficient for previous sensors whose sensitivity did not permit limb radiance measurements much above $70 \mathrm{~km}$ tangent height.

The assumption of LTE in the $\mathrm{CO}_{2}$ infrared bands and the assumption of uniformly mixed and well known $\mathrm{CO}_{2} \mathrm{vmr}$, described in the last paragraph, are no longer valid in the MLT region. The variability of $\mathrm{CO}_{2} \mathrm{vmr}$ requires that $\mathrm{T}_{\mathrm{k}}$ and $\mathrm{CO}_{2}$ vmr be retrieved simultaneously. SABER measures $\mathrm{CO}_{2}$ limb emission in the $15 \mu \mathrm{m}$ spectral interval to approximately $120 \mathrm{~km}$ in altitude for the purpose of determining $T_{k}$. SABER also observes $4.3 \mu \mathrm{m} \mathrm{CO} \mathrm{CO}_{2}$ limb emission to over $160 \mathrm{~km}$ altitude during the day and to approximately $130 \mathrm{~km}$ at night. Measurements of $\mathrm{CO}_{2} 15 \mu \mathrm{m}$ and $\mathrm{CO}_{2} 4.3 \mu \mathrm{m}$ limb radiance are combined to retrieve $\mathrm{T}_{\mathrm{k}}$ and $\mathrm{CO}_{2} \mathrm{vmr}$ in the MLT region. Non-LTE processes are rigorously accounted for in the retrieval scheme.

Derived profiles of $T_{k}$ in the MLT are necessary to understand the thermal structure of this region, one of SABER's primary goals. Accurate knowledge of $\mathrm{T}_{\mathrm{k}}$ and $\mathrm{CO}_{2}$ are necessary to quantify the radiative cooling of this region of the atmosphere, largely dominated by infrared emission from the $\mathrm{CO}_{2} 15 \mu \mathrm{m}$ bands. Moreover, $\mathrm{T}_{\mathrm{k}}$ is a key input into the retrieval of SABER's other data products. The global distribution of $\mathrm{CO}_{2}$ is interesting in its own right, as its latitudinal and seasonal variations are not well known and observed, and the mechanism for its departure from its uniformly mixed value is not well characterized.

In a previous work, Mertens et al. ${ }^{2}$ presented a non-LTE $\mathrm{T}_{\mathrm{k}}$ retrieval algorithm based on observations of $\mathrm{CO}_{2}$ $15 \mu \mathrm{m}$ broadband limb emission measurements, assuming $\mathrm{CO}_{2}$ abundance was known. They demonstrated the algorithm using model atmospheres, and studied the sensitivity of retrieved $\mathrm{T}_{\mathrm{k}}$ to key atmospheric and kinetic parameters used in the non-LTE $\mathrm{CO}_{2}$ model. One important conclusion from this work was that $\mathrm{CO}_{2} \mathrm{vmr}$ needed to be known to $15 \%$ or better in order to achieve SABER's goal of retrieving $\mathrm{T}_{\mathrm{k}}$ to $3 \mathrm{~K}$ or better below $100 \mathrm{~km}$. As a result of this study, the non-LTE $\mathrm{T}_{\mathrm{k}}$ retrieval algorithm of Mertens et al. has been expanded and updated to enable a simultaneous non-LTE retrieval of $\mathrm{T}_{\mathrm{k}}$ and $\mathrm{CO}_{2}$. In this paper, we present the salient features of the coupled non-LTE $\mathrm{T}_{\mathrm{k}} / \mathrm{CO}_{2}$ retrieval algorithm. The algorithm is demonstrated by showing preliminary retrievals from SABER measurements.

\section{RETRIEVAL APPROACH}

Kinetic temperature is retrieved in the stratosphere using SABER measured radiance from two $\mathrm{CO}_{2} 15 \mu \mathrm{m}$ channels, a narrow bandpass channel $\left(650-695 \mathrm{~cm}^{-1}\right)$ and a wide bandpass channel $\left(580-760 \mathrm{~cm}^{-1}\right)$. The two $\mathrm{CO}_{2}$ channels are used to register pressure with altitude in the stratosphere and infer $\mathrm{T}_{\mathrm{k}}$ assuming LTE conditions and assuming $\mathrm{CO}_{2}$ is uniformly mixed and known. This approach is similar to the two-color technique described in Ref.. ${ }^{1}$ The LTE assumption breaks down in the mesosphere for the infrared $\mathrm{CO}_{2}$ bands, and $\mathrm{CO}_{2}$ $\mathrm{vmr}$ is no longer uniformly mixed. The simultaneous non-LTE $\mathrm{T}_{\mathrm{k}} / \mathrm{CO}_{2}$ retrieval algorithm is then employed to infer $\mathrm{T}_{\mathrm{k}}$ and $\mathrm{CO}_{2} \mathrm{vmr}$ in MLT using measured radiance from the $\mathrm{CO}_{2} 15 \mu \mathrm{m}$ narrow channel and the $\mathrm{CO}_{2} 4.3$ $\mu \mathrm{m}$ channel $\left(2320-2400 \mathrm{~cm}^{-1}\right)$, respectively.

The LTE-retrieved $T_{k}$ and pressure described in the preceding paragraph provide the lower boundary conditions for the non-LTE $\mathrm{T}_{\mathrm{k}} / \mathrm{CO}_{2}$ retrieval. The lower boundary condition in the $\mathrm{CO}_{2}$ vibrational temperature model (described in the next section) is that the source function is given by the Planck function, requiring that 
the $\mathrm{CO}_{2}$ bands are optically thick and in LTE. In the retrieval inversion approach, pressure (p) is obtained by vertically integrating the barometric equation from the lower boundary altitude, requiring that the LTEretrieved $T_{k}(p)$ are accurate at the lower boundary altitude. Taking these factors into consideration, the lower boundary altitude of the non-LTE $\mathrm{T}_{\mathrm{k}} / \mathrm{CO}_{2}$ retrieval is nominally taken to be $40 \mathrm{~km}$.

The non-LTE $\mathrm{T}_{\mathrm{k}} / \mathrm{CO}_{2}$ retrieval model is comprised of two main components: (1) the forward radiance model and (2) the inversion model. These two components are described in more detail below.

\subsection{Forward Model}

The forward radiance model of the retrieval algorithm is the component that simulates the measured radiance along the limb line-of-sight. The forward model itself is composed of two parts: (1) the vibrational temperature model $\left(\mathrm{T}_{\mathrm{v}}\right)$ and $(2)$ the limb radiance model. Limb radiance is calculated using BANDPAK, ${ }^{3}$ now expanded for application to non-LTE calculations. ${ }^{4}$ The non-LTE formulation in BANDPAK is a broadband extension of the line-by-line approach described by Edwards et al ${ }^{5}$ and initially demonstrated by Mlynczak et al. ${ }^{6}$ There are eighteen $\mathrm{CO}_{2} 15 \mu \mathrm{m}$ bands and one $\mathrm{O}_{3} 14.1 \mu \mathrm{m}$ band that contribute to the total limb radiance in the $\mathrm{SABER}$ $\mathrm{CO}_{2} 15 \mu \mathrm{m}$ narrow channel spectral bandpass, i.e. above the lower boundary of the non-LTE $\mathrm{T}_{\mathrm{k}} / \mathrm{CO}_{2} \mathrm{retrieval}$ model. The SABER $4.3 \mu \mathrm{m}$ channel has seventeen $\mathrm{CO}_{2}$ bands that contribute to the total limb radiance at altitudes of approximately $70 \mathrm{~km}$ and above. Vibrational temperatures for the nineteen bands that emit in the $\mathrm{CO}_{2} 15 \mu \mathrm{m}$ narrow channel bandpass and the seventeen bands that emit in the $\mathrm{CO}_{2} 4.3 \mu$ m channel bandpass comprise the non-LTE inputs into the limb radiance model.

The nineteen bands that contribute to the total limb radiance in the SABER $\mathrm{CO}_{2} 15 \mu$ m narrow channel bandpass can be grouped into seven band-groups: the fundamental $\nu_{2}$ band of the major (626) isotope (010626); the fundamental $\nu_{2}$ bands of the minor $\left(636,628\right.$, and 627) isotopes (010-MIN); the first $\nu_{2}$ hot bands of the 626 isotope $(\{020\}-626)$; the first $\nu_{2}$ hot bands of the minor isotopes $\left(\{020\}\right.$-MIN); the second $\nu_{2}$ hot bands of the 626 isotope ( $\{030\}-626)$; the $\mathrm{O}_{3}$ major isotopic $\nu_{2}$ fundamental band; and the 'remaining' $\mathrm{CO}_{2}$ bands that contribute to the $\mathrm{CO}_{2} 15 \mu \mathrm{m}$ narrow channel limb radiance. Panels (a) and (b) of Figure 1 show SABER $\mathrm{CO}_{2} 15 \mu \mathrm{m}$ narrow channel limb radiance simulations for the US Standard model atmosphere: limb radiance from the seven band-groups listed above, the total limb radiance, the contribution of each band-group to the total limb radiance, and the noise level (NER: noise equivalent radiance) in the $\mathrm{SABER}_{\mathrm{CO}} \mathrm{CO}_{2} \mu \mathrm{m}$ narrow channel. The $\mathrm{CO}_{2}$ 'remainder' band contains contributions from all other $\mathrm{CO}_{2}$ bands found on the HITRAN 1996 database that are not specified in the band-groups above. Although there are no significant non-LTE effects in the limb radiance from these 'remainder' bands, their cumulative contribution to the total limb radiance is significant and must be modelled, as Figure 1 indicates. The $\mathrm{CO}_{2}$ 'remainder' band is treated as a pseudo-vibrational band - the non-LTE-to-LTE vibrational state population ratios (see Edwards et al. ${ }^{5}$ ) are set equal to the non-LTE-to-LTE population ratios of the 626 first $\nu_{2}$ hot band. This step eliminates anomalous thermospheric contributions and guarantees that the correct LTE contributions are included at altitude below approximately $70 \mathrm{~km}$, were their 'true' contribution becomes important, as Figure 1 indicates.

The bands that contribute most to the SABER $\mathrm{CO}_{2} 15 \mu \mathrm{m}$ narrow channel spectral bandpass are the 010$626,\{020\}-626$, and 010-MIN band-groups. The 010-626 band dominates the limb radiance except near $80 \mathrm{~km}$, where the $\{020\}-626$ and $010-$ MIN bands rival, if not exceed, the contribution due to 010-626. The contribution from the other band-groups are much smaller than those mentioned above; however, they must be rigorously modelled in order to retrieve $T_{k}$ accurately.

Analogous to the discussion of the bands that emit in the $\mathrm{SABER} \mathrm{CO}_{2} 15 \mu \mathrm{m}$ narrow channel bandpass, the seventeen bands that contribute to the total limb radiance in the $\mathrm{CO}_{2} 4.3 \mu \mathrm{m}$ channel can be grouped into six band-groups: the fundamental $\nu_{3}$ band of the 626 isotope (001-626); the fundamental $\nu_{3}$ bands of the minor isotopes (001-MIN); the first $4.3 \mu \mathrm{m}$ hot band of the 626 isotope (011-626); and the second, third and fourth $4.3 \mu \mathrm{m}$ hot bands of the 626 isotope $(\{021\}-626,\{031\}-626$, and $\{041\}-626))$. Panels (c) and (d) of Figure 1 for the SABER $\mathrm{CO}_{2} 4.3 \mu \mathrm{m}$ channel are analogous to panels (a) and (b) for the $\mathrm{CO}_{2} 15 \mu \mathrm{m}$ narrow channel. The bands that contribute most to the $\mathrm{CO}_{2} 4.3 \mu \mathrm{m}$ channel radiance are the 001-626, 001-MIN, 011-626, and \{021\}-626 band-groups. Above $110 \mathrm{~km}$, limb emission in the $4.3 \mu \mathrm{m}$ channel is dominated by the 001-626 band. Between $95 \mathrm{~km}$ and $110 \mathrm{~km}$, the four major band-groups mentioned above are comparable in their contribution 

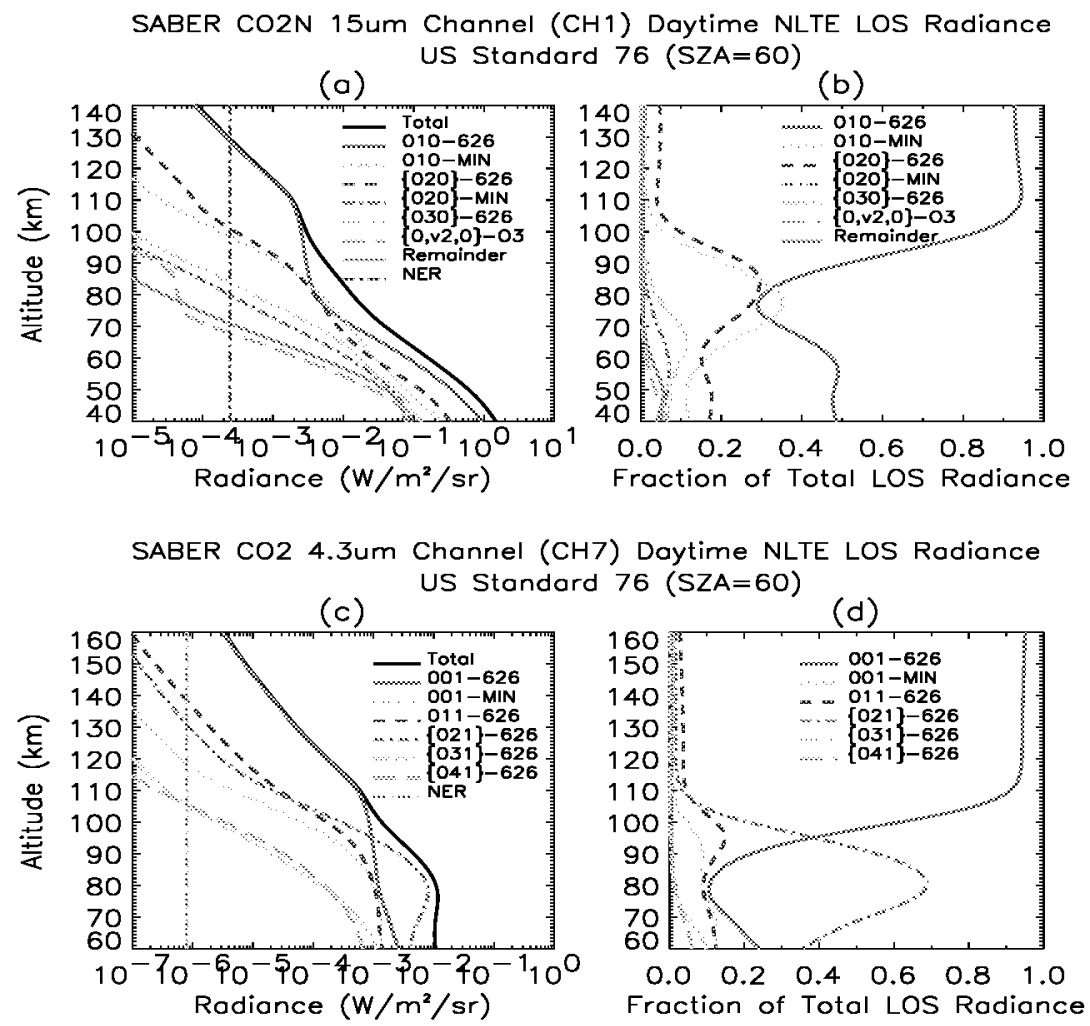

Figure 1. Simulations of daytime (solar zenith angle (SZA) 60 degrees) non-LTE line-of-sight (LOS) limb radiance for the SABER $\mathrm{CO}_{2} 15 \mu \mathrm{m}$ narrow channel (panels (a) and (b)) and $\mathrm{CO}_{2} 4.3 \mu \mathrm{m}$ channel (panels (c) and (d)) for the US Standard atmosphere. See text for details.

to the total limb radiance. Below $95 \mathrm{~km}$, limb emission is dominated by the $\{021\}-626$ band-group. However, similar to the case for the SABER $\mathrm{CO}_{2} 15 \mu \mathrm{m}$ narrow channel, all band-groups shown in panels (c) and (d) must be rigorously modelled in order to accurately retrieve $\mathrm{CO}_{2} \mathrm{vmr}$.

Figure 2 shows a model calculation of the $\mathrm{CO}_{2} \mathrm{~T}_{\mathrm{v}}$ 's for the US Standard atmosphere. The solar pumped states are shown in panels (a)-(d). The $15 \mu \mathrm{m} \mathrm{T}_{\mathrm{v}}$ 's are shown in panel (e). The solar pumped states are responsible for the emission in the SABER $\mathrm{CO}_{2} 4.3 \mu \mathrm{m}$ channel. Furthermore, they have an indirect affect on emission in the $\mathrm{CO}_{2} 15 \mu \mathrm{m}$ channel through collisional and radiative coupling to the $\mathrm{CO}_{2} \nu_{2}$ vibrational state manifold, as indicated in panel (f). The vibrational temperatures are calculated from the operational $\mathrm{CO}_{2} \mathrm{~T}_{\mathrm{v}}$ model, which is based on the Modified Curtis Matrix approach advanced by López-Puertas et al.. ${ }^{7}$ The operational $\mathrm{CO}_{2} \mathrm{~T}_{\mathrm{v}}$ model uses BANDPAK to perform all the radiation transfer calculations and will be described in more detail in Refs. ${ }^{4}$ and. $^{8}$

\subsection{Inversion Method}

Kinetic temperature and $\mathrm{CO}_{2} \mathrm{vmr}$ are retrieved by successively iterating between two independent retrieval modules: one for $\mathrm{T}_{\mathrm{k}}(\mathrm{p})$, assuming $\mathrm{CO}_{2}$ is known, and the other one for $\mathrm{CO}_{2} \mathrm{vmr}$, assuming $\mathrm{T}_{\mathrm{k}}(\mathrm{p})$ is known. The iteration stops when successive $\mathrm{CO}_{2}$ profiles have relaxed sufficiently over the altitude range of the non-LTE retrieval model. The global convergence criteria for the coupling between the $\mathrm{T}_{\mathrm{k}}$ and $\mathrm{CO}_{2}$ retrievals is that the average difference between two successive $\mathrm{CO}_{2} \mathrm{vmr}$ retrievals, i.e., averaged over all the retrieved tangent levels, does not exceed a user-specified percentage. Retrieval simulations for various model atmospheres (US 
C02 Daytime Vibrational Temperatures US Standard Daytime (SZA=60)
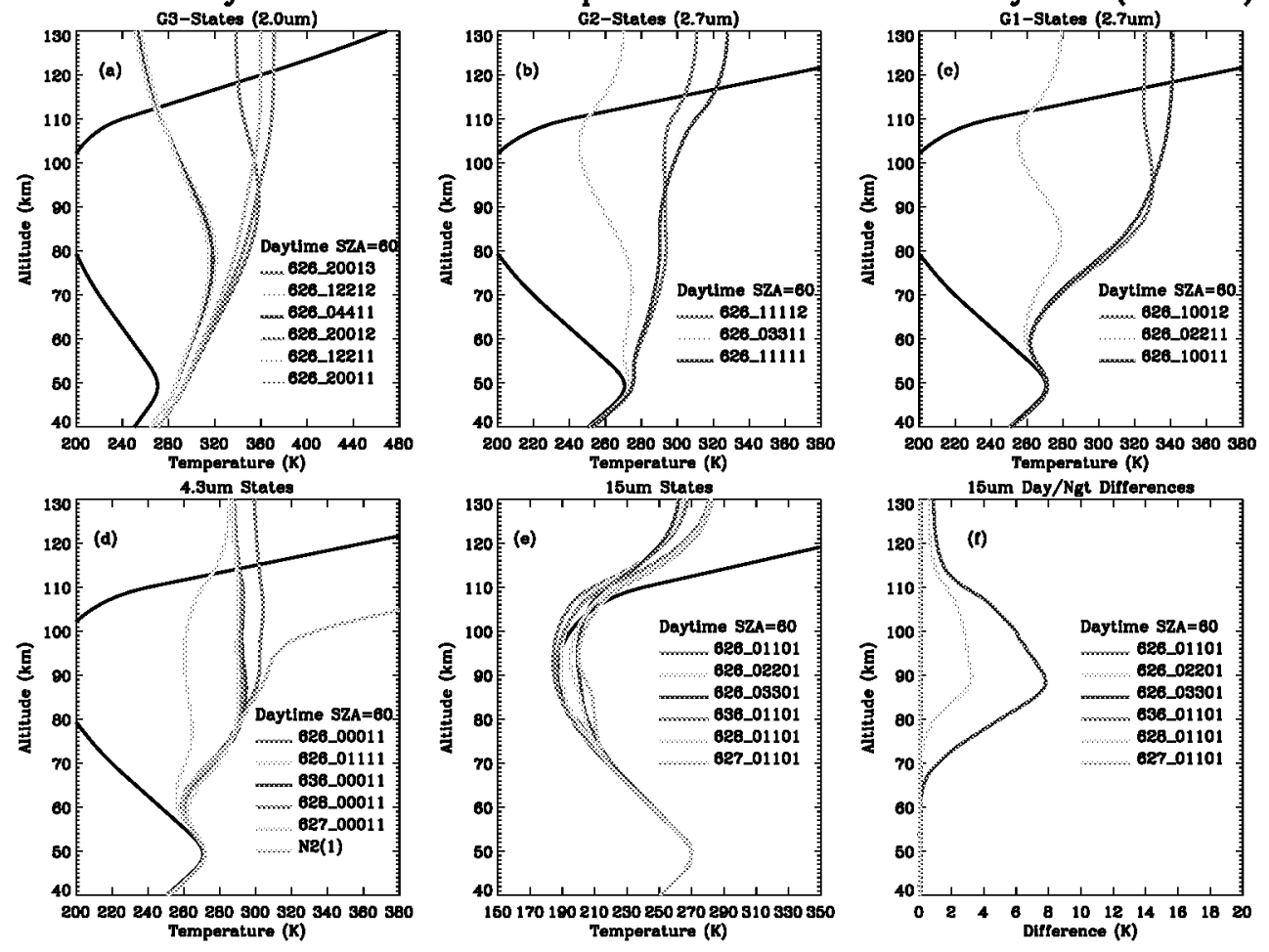

Figure 2. Simulations of daytime (solar zenith angel (SZA) 60 degrees) $\mathrm{CO}_{2}$ vibrational temperatures for US Standard atmosphere. See text for details.

Standard, Polar Summer, and Polar Winter) have shown that the differences between the last and next-to-thelast retrieved $\mathrm{CO}_{2}$ profiles are small enough not to significantly affect an additional $\mathrm{T}_{\mathrm{k}}$ retrieval; thus, justifying the termination of the non-LTE $\mathrm{T}_{\mathrm{k}} / \mathrm{CO}_{2}$ retrieval algorithm based on the convergence of the $\mathrm{CO}_{2}$ profile. Below we briefly describe the separate $\mathrm{T}_{\mathrm{k}}$ and $\mathrm{CO}_{2}$ retrieval modules. A detailed algorithm description will appear elsewhere. ${ }^{9}$

First we describe the non-LTE $\mathrm{T}_{\mathrm{k}}$ retrieval module. There are two primary relaxation loops. In the inner loop, a $\mathrm{T}_{\mathbf{k}}$ profile is retrieved using the onion-peel approach while pressure, $\mathrm{CO}_{2} \mathrm{vmr}$, and the $\mathrm{T}_{\mathbf{V}}$ 's are held fixed. Kinetic temperature is retrieved at each tangent altitude by adjusting the local $T_{k}$ until the modelled radiance matches the measured radiance within the convergence criterion. The temperature is adjusted using the Levenberg-Marquardt method. ${ }^{10}$ The inner loop convergence criterion is a requirement that the difference between successive iterations is much less than the expected errors in the solution. ${ }^{11}$ The fraction of the solution error required to satisfy the convergence criterion is user-specified.

The onion-peel approach is critical to retrievals from $\mathrm{CO}_{2}$ limb emission measurements in the MLT region, since the $\mathrm{CO}_{2} 15 \mu \mathrm{m}$ limb radiance for mesospheric tangent heights is dominated by emission from higher altitude layers. ${ }^{12}$ The same is also true for $\mathrm{CO}_{2} 4.3 \mu \mathrm{m}$ limb radiance. The onion-peel technique ensures that the modelled emission matches the measured radiance from the upper altitude layers, even though the retrieved temperature-pressure- $\mathrm{CO}_{2}$ combination may be incorrect at intermediate steps in the relaxation process. For a particular limb path, the effect is greater sensitivity to the local $T_{k}$ at the sought-after tangent altitude.

In the outer relaxation loop, the pressure profile is rebuilt from the lower boundary altitude using the onionpeel retrieved $T_{k}$ profile and the barometric pressure law. The vibrational temperatures are updated using the $\mathrm{CO}_{2} \mathrm{~T}_{\mathrm{v}}$ model with the previously retrieved $\mathrm{T}_{\mathrm{k}}, \mathrm{CO}_{2} \mathrm{vmr}$, and pressure profile as input. The onion-peel retrieval (inner loop) is repeated until the entire inferred $T_{k}$ profile relaxes within the convergence criterion, 
which is a requirement that the retrieved temperature profile differences between two successive onion-peel retrieval iterations be much smaller than the expected solution error at all tangent heights above the lower boundary altitude.

Next we describe the non-LTE $\mathrm{CO}_{2}$ vmr retrieval module. Because of the severe nonlinearities in the radiation transfer along the limb line-of-sight in the $\mathrm{SABER} \mathrm{CO}_{2} 4.3 \mu \mathrm{m}$ channel bandpass, the $\mathrm{CO}_{2} \mathrm{vmr}$ retrieval module is composed of a juxtaposition of two retrieval approaches. The first approach is the nonlinear relaxation method of Twomey-Chahine, ${ }^{13}$ modified here for limb path geometry and broadband radiance measurements. In the current approach, the kernel function, or weighting function, is the contribution of each layer along the limb line-of-sight to the total limb radiance, divided by the layer-averaged $\mathrm{CO}_{2}$ abundance. Similar to the non-LTE $\mathrm{T}_{\mathrm{k}}$ retrieval, the $\mathrm{CO}_{2}$ vmr is retrieved at each tangent altitude using the onion-peel method. The convergence criterion was described in the first paragraph of this section. If the criterion is not satisfied, the non-LTE $\mathrm{T}_{\mathrm{k}}$ retrieval is repeated, followed by a subsequent $\mathrm{CO}_{2}$ vmr retrieval using the modified Twomey-Chahine approach. Once the global convergence criterion is satisfied, one final $\mathrm{CO}_{2} \mathrm{vmr}$ retrieval is performed using the Levenberg-Marquardt approach, analogous to the inner loop relaxation scheme of the non-LTE $\mathrm{T}_{\mathrm{k}}$ retrieval described above.

The nonlinearities in the $\mathrm{CO}_{2} 4.3 \mu \mathrm{m}$ radiation transfer are too severe to use a retrieval algorithm based on Newtonian iteration, applicable to weakly nonlinear problems, ${ }^{14}$ or a Levenberg-Marquardt approach, applicable to moderately nonlinear problems. ${ }^{14}$ Consequently, the nonlinear relaxation method of TwomeyChahine is used to infer $\mathrm{CO}_{2}$ vmr in the coupled non-LTE $\mathrm{T}_{\mathbf{k}} / \mathrm{CO}_{2}$ retrieval algorithm. However, optimal estimation approaches, such as the Levenberg-Marquardt approach, provide useful statistical information: the estimated solution error, quality metrics such as the $\chi^{2}$, or penalty, function, and more theoretical-based convergence criterion. Therefore, the final $\mathrm{CO}_{2}$ vmr retrieval uses the Levenberg-Marquardt algorithm to refine the modified Twomey-Chahine approach and provide the useful statistical information described above.

\section{RESULTS AND DISCUSSION}

In this section we present preliminary non-LTE $\mathrm{T}_{\mathrm{k}} / \mathrm{CO}_{2}$ retrievals from SABER observations. There are a number of additional atmospheric parameters required as input into the $\mathrm{CO}_{2} \mathrm{~T}_{\mathrm{v}}$ model: $\mathrm{O}_{2}, \mathrm{~N}_{2}, \mathrm{O}\left({ }^{3} \mathrm{P}\right)$, and $\mathrm{O}\left({ }^{1} \mathrm{D}\right)$, for example. In the preliminary retrieved profiles shown in this section, the atmospheric parameters listed above were obtained from the TIMED-GCM climatology produced for SABER analysis.

Figure 3 shows nighttime non-LTE $\mathrm{T}_{\mathrm{k}}$ retrievals on March 3,2002 , near $69^{\circ} \mathrm{N}$. The retrieved $\mathrm{T}_{\mathrm{k}}$ profiles are compared to the Lübken and von $Z_{a h n}{ }^{15}$ climatological monthly mean $\mathrm{T}_{\mathrm{k}}$ profile for March. The monthly mean profile was generated from $T_{k}$ measurements taken from sodium lidar, falling spheres, and rocketborne mass spectrometer and ionization gauge measurements (see Ref. ${ }^{15}$ for details). Between $60 \mathrm{~km}$ and $105 \mathrm{~km}$, the differences between the individual SABER-derived $T_{k}$ profiles and the monthly mean profile are within the natural variability in the monthly mean $\mathrm{T}_{\mathrm{k}}$ profile for March at $69^{\circ} \mathrm{N} .{ }^{15}$ Below $60 \mathrm{~km}$ the SABER $\mathrm{T}_{\mathrm{k}}$ profiles are substantially cooler than the climatological mean; above $105 \mathrm{~km}$ the SABER $\mathrm{T}_{\mathrm{k}}$ profiles are substantially warmer than the climatological mean. Further analysis is required to understand these differences.

The following figures demonstrate the coupled non-LTE $\mathrm{T}_{k} / \mathrm{CO}_{2}$ retrieval algorithm for daytime SABER observations. Figure 4 shows retrieved $\mathrm{CO}_{2}$ profiles on January 28 and March 3, 2002. For each day, retrieved profiles are shown at latitudes of approximately $44^{\circ} \mathrm{N}$ and $27^{\circ} \mathrm{S}$. The retrieved profiles are shown as solid lines. Climatological mean $\mathrm{CO}_{2}$ profiles from the TIMED-GCM model are shown as dashed lines ${ }^{16}-$ which most closely correspond to the time, season and geo-location of the SABER measurements.

For equinox conditions, model simulations indicate that the latitudinal distribution of $\mathrm{CO}_{2}$ is symmetrically distributed about the equator (see Ref. ${ }^{17}$ and references therein). Consequently, the $\mathrm{CO}_{2}$ profiles for $\mathrm{March}$ 3 at $44^{\circ} \mathrm{N}$ and $27^{\circ} \mathrm{S}$ should be very similar, as Figure 4 indicates. However, SABER-derived $\mathrm{CO}_{2}$ profiles suggest a much larger depletion of $\mathrm{CO}_{2}$ in the upper mesosphere and lower thermosphere than predicted by the TIMED-GCM model and previous rocket borne mass spectrometer measurements, ${ }^{17}$ similar to the findings of other recent $\mathrm{CO}_{2}$ retrievals from infrared emission measurements (see Refs. ${ }^{18},{ }^{19}$ and ${ }^{20}$ ). From Figure 4 , the TIMED-GCM simulations predict that for equinox conditions, the $\mathrm{CO}_{2}$ abundance for $27^{\circ} \mathrm{S}$ is greater than 


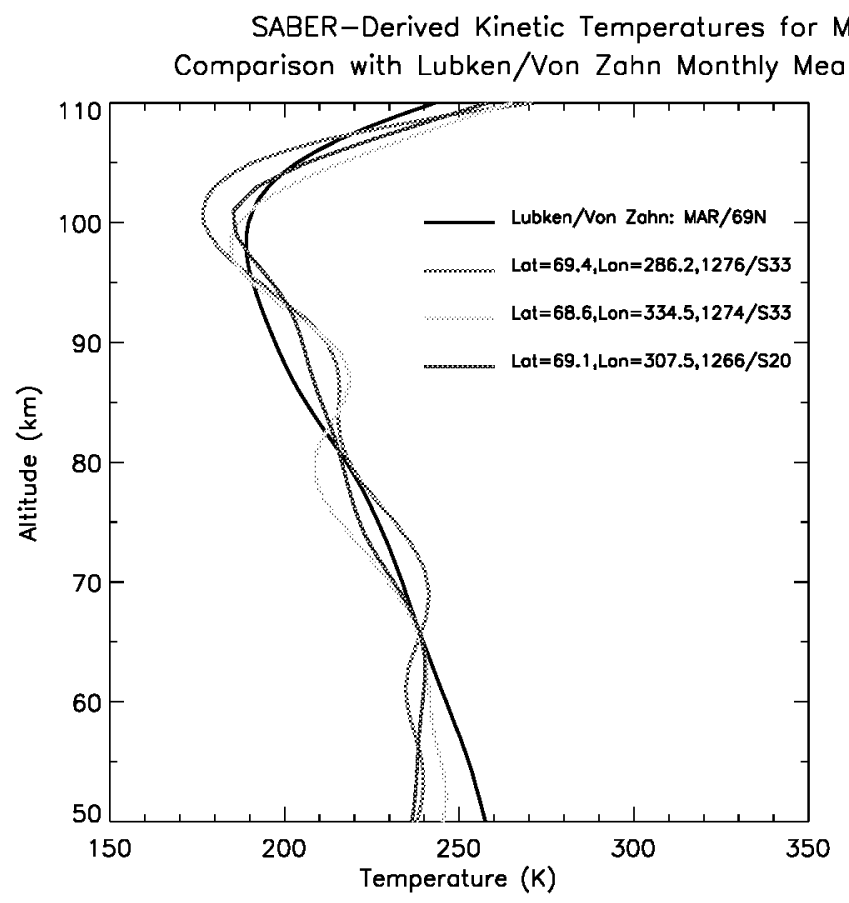

32002

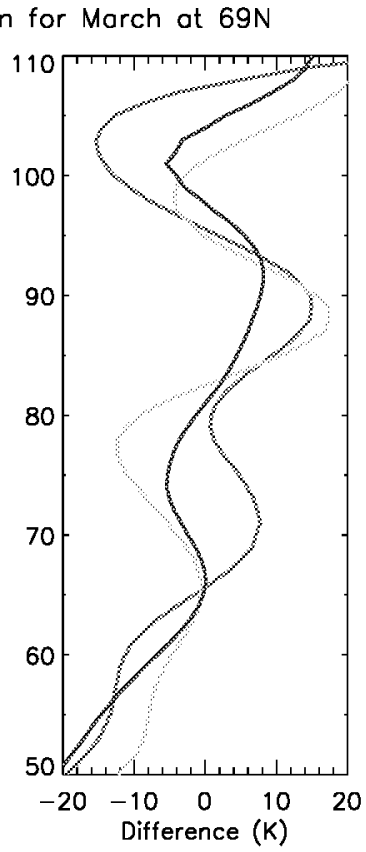

Figure 3. Nighttime non-LTE $T_{k}$ retrievals from SABER measurements on March 3, 2002, near $69^{\circ} \mathrm{N}$. The latitude, longitude, orbit and scan numbers, respectively, for the SABER measurements are indicated in the legend. The retrieved $\mathrm{T}_{\mathrm{k}}$ profiles are compared to the climatological monthly mean March $\mathrm{T}_{\mathrm{k}}$ profile from Lubken and von Zahn. ${ }^{15}$

the $\mathrm{CO}_{2}$ abundance for $44^{\circ} \mathrm{N}$ above $100 \mathrm{~km}$. The SABER retrievals show just the opposite effect: the $\mathrm{CO}_{2}$ abundance at $27^{\circ} \mathrm{S}$ is significantly depleted relative to the $\mathrm{CO}_{2}$ abundance at $44^{\circ} \mathrm{N}$.

Model simulations indicate that for solstice conditions, $\mathrm{CO}_{2}$ vmr remains constant up to higher altitudes in the summer hemisphere and departs from its constant value at lower altitudes in the winter hemisphere; an effect governed by upward transport in the summer hemisphere and downward transport in the winter hemisphere. ${ }^{17}$ SABER $\mathrm{CO}_{2}$ retrievals support this conclusion, as indicated in Figure 4 for the January 28 profiles. However, the retrieved $\mathrm{CO}_{2}$ profile at $44^{\circ} \mathrm{N}$ is significantly depleted with respect to the corresponding TIMED-GCM profile, while the corresponding TIMED-GCM profile for the $27^{\circ} \mathrm{S}$ measurement seems to fit the measurement scenario quite well.

Figure 5 shows the $T_{k}$ profiles that were retrieved simultaneously with the $\mathrm{CO}_{2}$ profiles shown in the previous figure. Similar to Figure 4, retrieved profiles are shown on January 28 and March 3, 2002, at approximately $44^{\circ} \mathrm{N}$ and $27^{\circ} \mathrm{S}$. Retrieved profiles are shown as solid lines and TIMED-GCM climatological mean $\mathrm{T}_{k}$ profiles are shown as dashed lines - which correspond most closely to the time, season and geo-location of the SABER measurements.

The most noticeable features in Figure 5 above $110 \mathrm{~km}$ are found in the $\mathbf{T}_{\mathrm{k}}$ profiles for January 28 and March 3 at $44^{\circ} \mathrm{N}$. There's an inversion layer in the January 28 profile and $\mathrm{T}_{\mathrm{k}}$ decreases with increasing altitude in the March 3 profile. Neither of these features are real; rather, they're due to large noise spikes in the $\mathrm{CO}_{2}$ $15 \mu \mathrm{m}$ narrow channel radiance profiles. In general, measurement noise will prohibit reasonable $T_{k}$ retrievals much above 110 to $115 \mathrm{~km}$.

The SABER-derived $T_{k}$ profiles in Figure 5 show a great deal of vertical wave structure, suggestive of rather strong tidal signatures. The SABER $T_{k}$ profiles are generally warmer than the TIMED-GCM profiles between 


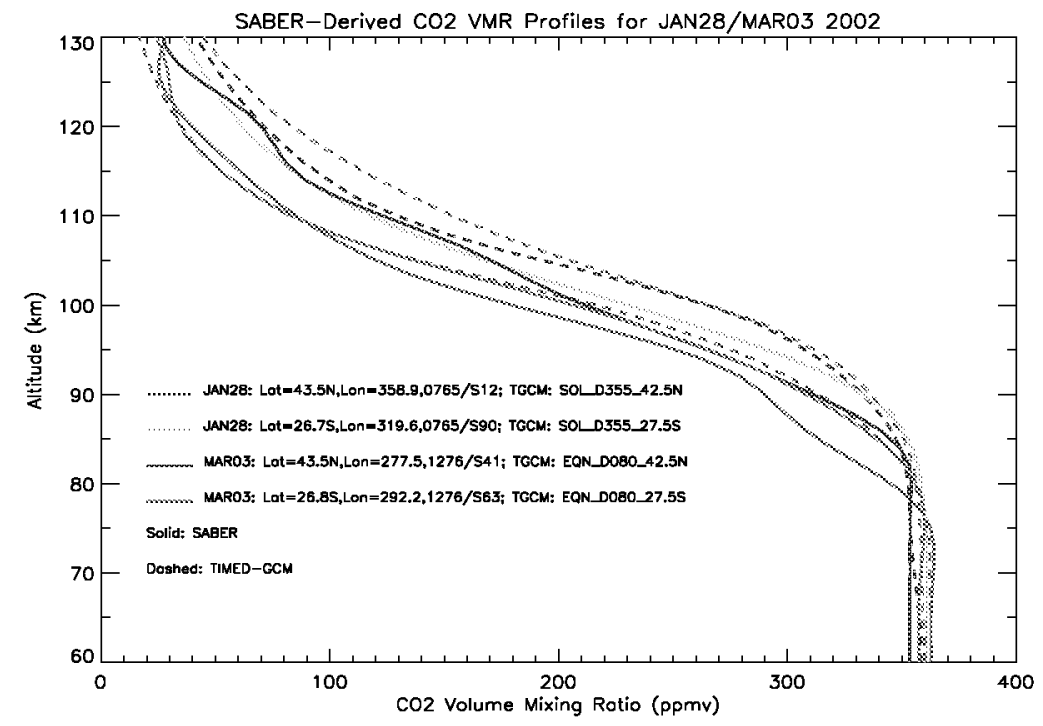

Figure 4. Daytime non-LTE $\mathrm{T}_{\mathrm{k}} / \mathrm{CO}_{2}$ retrievals from SABER measurements on January 28 and March 3,2002 . In this figure we show the retrieved $\mathrm{CO}_{2}$ profiles. The month, day, latitude, longitude, orbit and scan numbers, respectively, for the SABER measurements are indicated in the legend. The retrieved $\mathrm{CO}_{2}$ profiles are compared to the TIMED-GCM climatological mean that most closely corresponds to the SABER measurement time, season and geo-location. The TIMED-GCM profiles shown were computed for two time periods: daytime winter solstice (indicated by SOL_D355) and daytime spring equinox (indicated by EQN_D080).

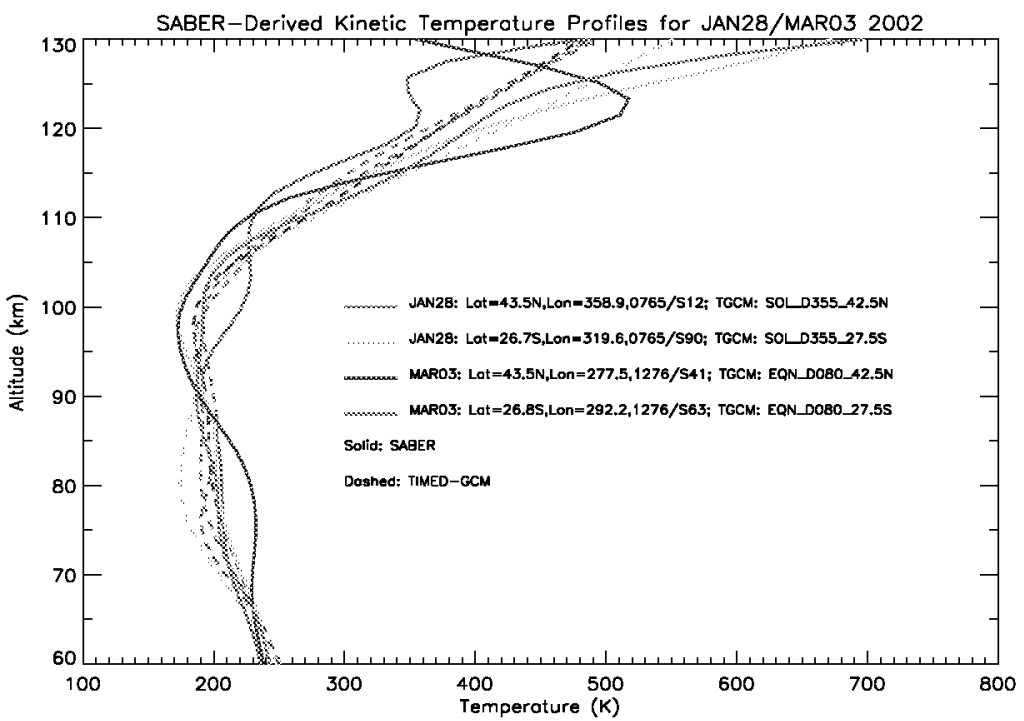

Figure 5. Daytime non-LTE $\mathrm{T}_{k} / \mathrm{CO}_{2}$ retrievals from SABER measurements on January 28 and March 3, 2002. In this figure we show the retrieved $T_{k}$ profiles. The month, day, latitude, longitude, orbit and scan numbers, respectively, for the SABER measurements are indicated in the legend. The retrieved $\mathrm{T}_{k}$ profiles are compared to the TIMED-GCM climatological mean that most closely corresponds to the SABER measurement time, season and geo-location. The TIMED-GCM profiles shown were computed for two time periods: daytime winter solstice (indicated by SOL_D355) and daytime spring equinox (indicated by EQN_D080). 
$70 \mathrm{~km}$ and $90 \mathrm{~km}$. In particular, the January 28 profile at $27^{\circ} \mathrm{S}$ and the March 3 profile at $44^{\circ} \mathrm{N}$ are significantly warmer than the model profiles between $70 \mathrm{~km}$ and $90 \mathrm{~km}$. On the other hand, the SABER $\mathrm{T}_{\mathrm{k}}$ profile for March 3 at $27^{\circ} \mathrm{S}$ is reasonably close to the corresponding TIMED-GCM profile below $110 \mathrm{~km}$. The SABER January 28 profile at $44^{\circ} \mathrm{N}$ has a feature that resembles a double mesopause region at approximately $93 \mathrm{~km}$ and $110 \mathrm{~km}$. The corresponding model profile has a double mesopause at approximately $75 \mathrm{~km}$ and $100 \mathrm{~km}$. For all the profiles shown in Figure 5, the SABER $\mathrm{T}_{\mathrm{k}}$ profiles are cooler than the TIMED-GCM profiles below approximately $65 \mathrm{~km}$.

\section{CONCLUSIONS}

In this paper we briefly described the coupled non-LTE $\mathrm{T}_{\mathrm{k}} / \mathrm{CO}_{2}$ retrieval algorithm used to infer $\mathrm{T}_{\mathrm{k}}$ and $\mathrm{CO}_{2}$ vmr from limb emission measurements observed from SABER's $\mathrm{CO}_{2} 15 \mu \mathrm{m}$ and $\mathrm{CO}_{2} 4.3 \mu \mathrm{m}$ broadband radiometer channels. We have shown preliminary $\mathrm{T}_{\mathrm{k}} / \mathrm{CO}_{2}$ profiles from SABER observations. The preliminary results look reasonable. Nighttime $T_{k}$ retrievals near $69^{\circ} \mathrm{N}$ generally compare favorably with the Lübken and von Zahn climatology. Daytime $T_{k}$ retrievals compare reasonably well with TIMED-GCM profiles, although some of the SABER $\mathrm{T}_{\mathrm{k}}$ profiles seem to be modulated by quite large tidal signatures. Retrieved $\mathrm{CO}_{2} \mathrm{vmr}$ profiles seem to confirm that models (e.g., TIMED-GCM) tend to overpredict $\mathrm{CO}_{2}$ in the MLT region.

At the time of this writing, a number of instrument corrections are being made to improve the overall quality of the SABER radiance measurements. The non-LTE $\mathrm{T}_{\mathrm{k}} / \mathrm{CO}_{2}$ retrieval algorithm presented here is currently being interfaced and ingested into the overall SABER software system. In the near future, a number of important atmospheric input parameters (i.e., input into the $\mathrm{CO}_{2} \mathrm{~T}_{\mathrm{v}}$ model) will be derived below 100 $\mathrm{km}$ from SABER observations - for example, $\mathrm{O}\left({ }^{3} \mathrm{P}\right)$ and $\mathrm{O}\left({ }^{1} \mathrm{D}\right)$. Thus, the excellent quality of the SABER measurements combined with the non-LTE $\mathrm{T}_{\mathbf{k}} / \mathrm{CO}_{2}$ retrieval algorithm presented here, and along with the

other SABER non-LTE retrievals algorithms, offer the potential to significantly improve our understanding of the MLT thermal structure, chemistry, and energetics.

\section{ACKNOWLEDGMENTS}

M.L-P. has been partially supported by MCYT under contracts PNE-017/2000-C and REN2001-3249. RHP and and JRW are grateful to Kent Miller of the Air Force Office of Scientific Research for partial support of this work. The work of PPW was carried out under contract to Air Force Research Laboratories under contract F19628-96-C-0048. All authors acknowledge support from NASA Langley under its SABER project.

\section{REFERENCES}

1. J. C. Gille and F. B. House, "On the inversion of limb radiance measurments. I: Temperature and thickness", J. Atmos. Sci. 28, pp. 1427-1442, 1971.

2. C. J. Mertens, M. G. Mlynczak, M. López-Puertas, P. P. Wintersteiner, R. H. Picard, J. R. Winick, L. L. Gordley, and J. M. Russell III, "Retrieval of mesospheric and lower thermospheric kinetic temperature from measurements of $\mathrm{CO}_{2} 15 \mu \mathrm{m}$ Earth limb emission under non-LTE conditions", Geophys. Res. Lett., 28, pp. 1391-1394, 2001.

3. B. T. Marshall, L. L. Gordley, and D. A. Chu, "BANDPAK: Algorithms for modeling broadband transmission and radiance", J. Quant. Spectrsc. Radiat. Transfer 52, pp. 581-599, 1994.

4. C. J. Mertens, M. G. Mlynczak, M. Lópes-Puertas, P. P. Wintersteiner, R. H. Picard, J. R. Winick, B. T. Marshall, L. L. Gordley, and J. M. Russell III, "Line-by-line and broadband non-LTE radiation transfer algorithms for the operational processing of satellite data", manuscript in preparation.

5. D. P. Edwards, M. López-Puertas, and M. A. López-Valverde, "Non-LTE thermodynamic equilibrium studies of the $15-\mu \mathrm{m}$ bands of $\mathrm{CO}_{2}$ for atmospheric remote sensing", J. Geophys. Res. 98, pp. 14,955$14,977,1993$.

6. M. G. Mlynczak, D. S. Olander, and M. López-Puertas, "Rapid computation of spectrally integrated nonLTE limb emission", J. Geophys. Res. 99, pp. 25,761-25,772, 1994. 
7. M. López-Puertas, G. Zaragoza, M. A. López-Valverde, and F. W. Taylor, "Non local thermodynamic equilibrium (LTE) atmospheric limb emission at $4.6 \mu \mathrm{m}$. 1. An update of the $\mathrm{CO}_{2}$ non-LTE radiation tranfer model", J. Geophys. Res., 103, pp. 8499-8513, 1998.

8. P. P. Wintersteiner, M. López-Puertas, C. J. Mertens, R. H. Picard, and J. R. Winick, "Comparison of three algorithms for evaluating non-LTE populations of $\mathrm{CO}_{2}$ states in the middle atmosphere", manuscript in preparation.

9. C. J. Mertens, M. G. Mlynczak, M. López-Puertas, P. P. Wintersteiner, R. H. Picard, J. R. Winick, L. L. Gordley, and J. M. Russell III, "Simultaneous retrieval of temperature and $\mathrm{CO}_{2}$ abdundance from measurements of $\mathrm{CO}_{2} 15 \mu \mathrm{m}$ and $4.3 \mu \mathrm{m}$ earth limb emission measurements under non-LTE conditions: Algorithm description and results", manuscript in preparation.

10. W. H. Press, S. A. Teukolsky, W. T. Vetterling, and B. P. Flannery, Numerical Recipes in Fortran, Second Edition, p. 678, Cambridge University Press, New York, 1992.

11. C. J. Marks and C. D. Rodgers, "A Retrieval Method for Atmospheric Composition From Limb Emission Measurements", J. Geophys. Res., 98, pp. 14,939-14,953, 1993.

12. P. P. Wintersteiner, R. H. Picard, R. D. Sharma, J. R. Winick, and R. A. Joseph, "Line-by-line radiative excitation model for the non-equilibrium atmosphere: Application to $\mathrm{CO}_{2} 15-\mu \mathrm{m}$ emission", J. Geophys. Res., 97, pp. 18,083-18,117, 1992.

13. S. Twomey, B. Herman, and R. Rabinoff, "An Extension of the Chahine Method of Inverting the Radiation Transfer Equation”, J. Atmos. Sci., 34, pp. 1085-1090, 1977.

14. C. D. Rodgers, Inverse Methods for Atmospheric Sounding: Theory and Practice, World Scientitic, 2000.

15. F. -J. Lüken and U. von Zahn, "Thermal Structure of the Mesopause region at Polar Latitudes", J. Geophys. Res., 96, pp. 20,841-20,857, 1991.

16. R. G. Roble, "On the feasibility of developing a global atmospheric model extending from the ground to the exosphere", Atmospheric Science Across the Stratopause, Geophysical Monograph 123, American Geophysical Union, 2000.

17. M. López-Puertas, M. Á. López-Valverde, R. R. Garcia, and R. G. Roble, "A review of $\mathrm{CO}_{2}$ and $\mathrm{CO}$ abundances in the middle atmosphere", Atmospheric Science Across the Stratopause, Geophysical Monograph 123, American Geophysical Union, pp.83-100, 200.

18. M. López-Puertas, G. Zaragoza, M. A. López-Valverde, and F. W. Taylor, "Non local thermodynamic equilibrium (LTE) atmospheric limb emission at $4.6 \mu \mathrm{m} \mathrm{2.} \mathrm{An} \mathrm{analysis} \mathrm{of} \mathrm{the} \mathrm{daytime} \mathrm{wideband} \mathrm{radiances}$ as measured by UARS improved stratospheric and mesospheric sounder", J. Geophys. Res., 103, pp. 8515$8530,1998$.

19. G. Zaragoza, M. López-Puertas, M. Á. López-Valverde, and F. W. Taylor, "Global distribution of $\mathrm{CO}_{2}$ in the upper mesosphere as derived from UARS/ISAMS measurements", J. Geophys. Res., 105, pp. 19,829$19,839,2000$.

20. M. Kaufmann, O. A. Gusev, K. U. Grossmann, R. G. Roble, M. E. Hagan, and C. Hartsough, and A. A. Kutepov, "The vertical and horizonal distribution of $\mathrm{CO}_{2}$ densities in the upper meosphere and lower thermosphere as measured by CRISTA", accepted by J. Geophys. Res. 